\title{
Plasminogen Interacts with Human Platelets through Two Distinct Mechanisms
}

\author{
Lindsey A. Miles, Mark H. Ginsberg, James G. White, and Edward F. Plow \\ Department of Immunology, Research Institute of Scripps Clinic, La Jolla, California 92037; \\ and University of Minnesota Medical School, Minneapolis, Minnesota 55455
}

\begin{abstract}
Glu-plasminogen, the native form of plasminogen, interacts in a specific and saturable manner with unstimulated human platelets, and the binding is enhanced fivefold by thrombin stimulation (Miles and Plow, 1985. J. Biol. Chem. 260:4303). This study characterizes the nature of the Glu-plasminogen binding sites by analyzing platelets deficient in selected proteins and functions. Platelets from patients with afibrinogenemia, Gray platelet syndrome, and the Cam Variant of thrombasthenia, a form of thrombasthenia with near normal levels of glycoprotein IIb/IIIa (GPIIb/IIIa), showed minimal augmentation of plasminogen binding to thrombin-stimulated platelets but normal binding to unstimulated platelets. This selective deficiency indicates that two distinct mechanisms are involved in the interaction of plasminogen with platelets. These abnormal platelets share a deficiency in fibrinogen. Surface expression of platelet fibrinogen, however, was not sufficient for enhanced plasminogen binding to stimulated platelets, and experiments with alpha-thrombin and gamma-thrombin indicated that fibrin formation on the platelet surface is necessary for the augmented plasminogen binding. Unstimulated and stimulated thrombasthenic platelets deficient in GPIIb/IIIa bound markedly reduced levels of plasminogen, which suggests a role for GPIIb/IIIa in plasminogen binding to unstimulated platelets. Treatment of platelets to dissociate the heterodimeric complex of GPIIb/IIIa did not significantly perturb plasminogen binding to unstimulated platelets, but the complex may be necessary for thrombin-stimulated plasminogen binding via its interaction with platelet fibrin.
\end{abstract}

\section{Introduction}

Platelets possess both pro-fibrinolytic and anti-fibrinolytic activities $(1,2)$, and the proximal relationship between platelets and fibrin within thrombi suggests that these activities may contribute to the regulation of fibrinolysis. Interaction of plasminogen with platelets provides one mechanism by which platelets might participate in fibrinolysis. Early evidence in the literature suggested this possibility $(1,3)$. We have recently demonstrated specific and saturable binding of plasminogen to platelets (4). This interaction occurred with high capacity: at saturation, resting and thrombin stimulated platelets bound 37,000 $\pm 10,000$ and 190,000 $\pm 45,000$ plasminogen molecules/cell, respectively. The apparent dissociation constants $\left(K_{d}\right)$ for the interaction of

Portions of this work were presented at the Xth International Congress on Thrombosis and Haemostasis, San Diego, CA, July, 1985.

Received for publication 20 August 1985 and in revised form 15 January 1986.

J. Clin. Invest.

(C) The American Society for Clinical Investigation, Inc.

0021-9738/86/06/2001/09 \$1.00

Volume 77, June 1986, 2001-2009 plasminogen with resting and thrombin-stimulated platelets were similar (1.9-2.6 $\mu \mathrm{M})$. Thus, it was not possible to determine whether the enhanced plasminogen binding observed after platelet stimulation reflected an extension of the same binding mechanism observed on resting cells or involved an independent one.

The high binding capacity of platelets for plasminogen restricts the candidate binding sites to only major platelet constituents. For example, platelets contain alpha ${ }_{2}$-antiplasmin and histidine-rich glycoprotein, which are known to bind plasminogen (5-7), but the concentrations of these proteins (530 [8] and 3,700 [9] molecules/platelet, respectively) are too low to account readily for the capacity of platelets for plasminogen. Of the platelet surface membrane proteins, GPIb at $26,000 \pm 10,000$ copies per platelet (10) and glycoprotein IIb/IIIa (GPIIb/IIIa) at $40,000-50,000$ copies per platelet $(11,12)$ are potential candidates for plasminogen binding sites on resting platelets. Since agonists alter the function of both of these membrane proteins as evidenced by ristocetin-supported binding of von Willebrand Factor to GPIb $(10,13)$ and the role of GPIIb/IIIa in thrombinstimulated binding of fibrinogen $(12,14-16)$, fibronectin (17), and von Willebrand Factor (18), their alteration may also contribute to the increase in plasminogen binding to stimulated platelets. Thrombin stimulation also results in the expression of new species on the surface of activated platelets. Fibrinogen and thrombospondin are major platelet alpha granule constituents that become expressed on the surface of stimulated platelets (19, 20). Thrombospondin binds plasminogen with high affinity (21). Fibrin, which may be formed on the platelet surface as a result of the proteolytic action of thrombin on released platelet fibrinogen, binds Glu-plasminogen with considerably greater affinity than does fibrinogen (22). Thrombospondin at 99,000 trimeric subunits/platelet (23) and fibrinogen at 126,000 molecules/ platelet (24) are present at sufficient concentrations to contribute to plasminogen binding to the stimulated cells.

In this study, we have used various conditions of stimulation and membrane perturbation and platelets congenitally deficient in surface glycoproteins and/or internal pools of proteins to assess possible contributions of specific platelet proteins to the interaction of plasminogen with stimulated and unstimulated platelets. Our results show that distinct mechanisms are involved in the binding of plasminogen to unstimulated and thrombinstimulated platelets. Moreover, platelet molecules that may directly mediate or participate in the binding of plasminogen are identified.

\section{Methods}

Plasminogen. Glu-plasminogen was isolated from fresh frozen human plasma by affinity chromatography on lysine-Sepharose (25) in the presence of $1 \mathrm{mM}$ benzamidine, $0.02 \% \mathrm{NaN}_{3}$, and $0.003 \mathrm{M}$ EDTA, followed by molecular exclusion chromatography on Ultrogel AcA44 (26). The plasminogen was $\geq 95 \%$ pure as assessed by Coomassie Blue staining of $10 \%$ polyacrylamide gels in the presence of sodium dodecyl sulfate (SDS) 
as previously described (4). Plasminogen concentrations were determined spectrophotometrically at $280 \mathrm{~nm}$ using the extinction coefficient of 16.8 (27), and the absence of Lys-plasminogen in the Glu-plasminogen preparations was established by amino-terminal analyses (28). Plasminogen was labeled by a modified chloramine-T procedure as previously described (29). Specific activities of the ${ }^{125}$ I-plasminogen preparations used during the course of these studies were $0.6 \pm 0.2 \mu \mathrm{Ci} / \mu \mathrm{g}$, and the precipitability of the radioactivity in $13 \%$ trichloroacetic acid was $\geq 95 \%$. As previously reported from our laboratory (4) and verified with each preparation used in the present study, when the ${ }^{125} \mathrm{I}$-plasminogen preparations were run on $10 \%$ polyacrylamide gels in the presence of SDS under either reducing or nonreducing conditions $\geq 90 \%$ of the applied radioactivity migrated as a single peak with the same mobility as unlabeled plasminogen. In addition, when analyzed by slicing and counting alkali gels under nondenaturing conditions, the ${ }^{125}$ I-plasminogen preparation migrated as a single band with a similar mobility to the single band observed on stained gels with unlabeled plasminogen.

Anti-fibrinogen $F\left(a b^{\prime}\right)_{2}$ fragments. Antibodies to human fibrinogen were raised by biweekly injections of human fibrinogen in complete Freund's adjuvant into goats. To prepare $F\left(a^{\prime}\right)_{2}$ fragments, we precipitated the antiserum with ammonium sulfate at $35 \%$ saturation. The precipitate was dissolved in $\mathrm{H}_{2} \mathrm{O}$, and dialyzed into $0.12 \mathrm{M} \mathrm{Na}$ acetate, pH 3.8, $0.05 \mathrm{M} \mathrm{NaCl}, 0.1 \% \mathrm{NaN}_{3}$. This material was then digested with $3 \mathrm{mg}$ pepsin/100 mg protein for $18 \mathrm{~h}$ at $37^{\circ} \mathrm{C}$, dialyzed into $0.01 \mathrm{M} \mathrm{Na}$ phosphate, $0.15 \mathrm{M} \mathrm{NaCl}$, pH 7.3 and immunopurified on a column of fibrinogen-Sepharose. Bound $\mathrm{F}\left(\mathrm{ab}^{\prime}\right)_{2}$ fragments were eluted with $0.1 \mathrm{M}$ glycine $\mathrm{HCl}, \mathrm{pH} 2.2,10^{-4} \mathrm{M}$ phenylmethylsulfonyl fluoride (PMSF), ${ }^{1}$ $0.02 \% \mathrm{NaN}_{3}$, neutralized with $\mathrm{NaOH}$ to $\mathrm{pH} 7.0$, dialyzed into phosphatebuffered saline (PBS), and radioiodinated by a modified chloramine $T$ procedure (30) to specific activities of $1.4 \pm 0.8 \mu \mathrm{Ci} / \mu \mathrm{g}$. The ${ }^{125} \mathrm{I}$-labeled $\mathrm{F}\left(\mathrm{ab}^{\prime}\right)_{2}$ preparations and extracts of platelets with bound antibody fragments were analyzed on polyacrylamide gels in the presence of SDS. Based upon densitometric scans of the autoradiographs of these gels, only $12 \%$ intact IgG was detected in the starting preparation and $7 \%$ in the platelet bound material.

Radioimmunoassays (RIAs). Plasma and platelet fibrinogen were quantitated in a double antibody RIA as previously described (30). Platelets $\left(5 \times 10^{8}\right)$ were lysed in $0.5 \mathrm{ml}$ of $0.5 \%$ Triton X $100,5 \mathrm{mM}$ EDTA, and $1 \mathrm{mM}$ PMSF. The fibrinogen content of these lysates was determined relative to a standard of purified plasma fibrinogen diluted into the Triton mixture. Fibrinopeptide A release was also determined in a double-antibody RIA. Supernatants derived from stimulated platelets were precipitated with an equal volume of $60 \%$ ethanol, $0.625 \%$ human IgG, $1 \mathrm{mM}$ PMSF, and $5 \mathrm{mM}$ EDTA (31) before analyses. Platelet thrombospondin was quantitated by RIA of cell lysates as previously described (23).

Platelet isolation and binding assays. Human blood donated by healthy volunteers was collected into acid-citrate-dextrose, and platelets were isolated by differential centrifugation followed by gel filtration on Sepharose 2B in divalent ion free Tyrode's buffer, pH 7.2, containing $20 \mathrm{mg} / \mathrm{ml}$ bovine serum albumin (BSA) (32). The washed platelets were counted in a Coulter model II counter (Coulter Electronics, Inc., Hialeah, FL). In the binding assays, $40 \mu \mathrm{l}$ of washed human platelets at $5 \times 10^{8}$ $\mathrm{ml}$ in the Tyrode's buffer, were incubated with $0.1-0.2 \mu \mathrm{M}^{125} \mathrm{I}$-plasminogen, that had been precentrifuged for $5 \mathrm{~min}$ in a microfuge (Beckman Instruments, Inc., Fullerton, CA). Precentrifugation of the ${ }^{125}$ I-plasminogen resulted in loss of $\leq 6 \%$ of the radioactivity. Unless otherwise indicated (i.e., experiments shown in Table IV), various stimuli, unlabeled plasminogen, or divalent cations were added simultaneously to a final volume of $200 \mu \mathrm{l}$. After incubation at selected temperatures for selected times, triplicate $50-\mu \mathrm{l}$ samples were individually layered onto $300 \mu \mathrm{l}$ of $20 \%$ sucrose in Tyrode's buffer in $\mathbf{5 0 0 \mu l}$ conical polypropylene tubes and centrifuged for $2.5 \mathrm{~min}$ in a Beckman microfuge B (Beckman Instruments, Inc.). Tips were amputated and counted in an Iso-Data gamma counter (Iso-Data, Inc., Palatine, IL). Molecules of plasminogen bound

1. Abbreviations used in this paper: PMSF, phenylmethylsulfonyl fluoride. were calculated from the specific activity of the radiolabeled plasminogen using a molecular weight of 90,000 . We have reported previously that $10^{8}$ platelets contain $21 \mathrm{ng}$ plasminogen (4). Therefore, in binding assays using $\geq 0.1 \mu \mathrm{M}^{125}$ I-plasminogen, if fully released, platelet plasminogen would occupy $<0.01 \%$ of the binding sites on the cells and would not appreciably change the specific activity of the ligand. In experiments with abnormal platelets in which apparent dissociation constants and the number of binding sites for plasminogen were determined, varying concentrations of unlabeled plasminogen were added to the platelets with a constant amount $(0.1-0.2 \mu \mathrm{M})$ of ${ }^{125}$ I-plasminogen. As a relatively low affinity system, it was not feasible to add sufficient unlabeled plasminogen to ensure that all residual radioactivity bound at high concentrations of unlabeled plasminogen represented nonspecific binding. Therefore, nonspecific binding was treated as a fitted parameter in the ligand computer program of Munson and Rodbard (33) as modified by Shih. As previously published (4), this analysis provided estimates for the nonspecific binding of the ligand to thrombin-stimulated and resting platelets of 0.14 and $0.17 \%$ of total added ligand. These values were used to calculate nonspecific binding at input concentrations of plasminogen utilized in the present study. Accordingly, at a $0.1 \mu \mathrm{M}$ input concentration of ${ }^{125} \mathrm{I}$-plasminogen, $12 \%$ of the total binding to thrombin-stimulated platelets and $25 \%$ of the binding to unstimulated platelets was calculated to be nonspecific. At the highest concentrations of unlabeled plasminogen added (10-30 $\mu \mathrm{M})$, the residual amount of radioactivity associated with stimulated and unstimulated platelets during the course of these studies was 14.2 and $25.9 \%$, indicating the validity of the estimates for nonspecific binding. Since nonspecific binding was relatively low at $0.1-0.2 \mu \mathrm{M}$ added plasminogen, this concentration was utilized in experiments in which a single dose of ligand was added.

Binding of radiolabeled anti-fibrinogen $\mathrm{F}\left(\mathrm{ab}^{\prime}\right)_{2}$ fragments was measured in a similar way with an input radiolabeled ligand concentration of $4.4 \times 10^{-8} \mathrm{M}$, determined to be a saturating concentration. ${ }^{125} \mathrm{I}-\mathrm{Fi}-$ brinogen binding to platelets was measured as previously described (32).

Abnormal platelets. The Gray platelets (24), Bernard Soulier platelets $(10,34)$, afibrinogenemic platelets $(35)$, thrombasthenic platelets $(36)$, and Cam Variant thrombasthenic platelets (37) used in this study have been previously characterized. The thrombasthenic platelets had reduced fibrinogen, $\leq 10 \%$ GPIIb/IIIa content as determined by monoclonal antibody binding and very low fibrinogen receptor expression in response to ADP. As previously reported (37), and detailed in a submitted manuscript (Ginsberg, M. H., A. Lightsey, T. J. Kunicki, A. Kaufman, G. Marguerie, and E. F. Plow, manuscript submitted for publication), Cam Variant platelets also have reduced platelet fibrinogen levels $(\leq 3 \%$ of normal), markedly reduced ADP-induced fibrinogen receptor expression, fail to aggregate in response to ADP or thrombin, and have near-normal levels of GPIIb/IIIa accessible to lactoperoxidase-catalyzed surface radioiodination. The Gray platelets have reduced contents of alpha granule proteins including fibrinogen, thrombospondin, platelet factor 4 (PF4), and platelet-derived growth factor (24). The only defect observed in the afibrinogenemic platelets used in this study is decreased platelet fibrinogen content, and these platelets have been shown to aggregate and bind fibrinogen normally when provided with extracellular fibrinogen (35). The Bernard-Soulier platelets have reduced levels of GPIb and do not aggregate or bind von Willebrand Factor in response to ristocetin $(10,34)$. The Gray, Bernard-Soulier, and thrombasthenic platelets and their normal control platelets, drawn in parallel, required overnight shipping before isolation. In some cases, the extent of plasminogen binding of the normal platelets shipped in parallel was reduced compared to freshly isolated, normal platelets. For example, the control platelets shipped with the thrombasthenic platelets bound 400-1,800 plasminogen molecules/ platelet at an input ${ }^{125} \mathrm{I}$-plasminogen concentration of $0.2 \mu \mathrm{M}$ compared with $3,700 \pm 1,050$ molecules per cell for freshly isolated platelets (4). Thrombin stimulation of the shipped platelets, however, still resulted in a three- to fivefold enhancement in plasminogen binding. Therefore, binding data from these experiments were expressed as a percent of the binding to the control platelets.

Reagents. Fibrinogen was isolated (38) and radiolabeled as previously described (32). Human alpha-thrombin and gamma-thrombin were 
kindly provided by Dr. John Fenton, New York State Department of Health, Albany, NY. The activities of these thrombin preparations were determined using the tripeptide substrate, S2238, H-D-phenylalanyl-Lpipecolyl-L-arginine-p-nitroanilide dihydrochloride (Kabi, Sweden) according to the manufacturer's directions. Antiserum to fibrinopeptide A was a generous gift from Dr. Karen Kaplan and Dr. John Owen, Columbia University, New York, NY. AP-2, a monoclonal antibody reactive with the GPIIb/IIIa complex in the presence of calcium but not with separated constituents in the presence of EDTA or calcium as monitored by crossed immunoelectrophoresis $(39,40)$, was kindly provided by Dr. Thomas Kunicki, Blood Center of Southeastern Wisconsin, Milwaukee, WI.

Sepharose resin was from Pharmacia (Uppsala, Sweden) and Ultrogel AcA44 was from LKB (Industrie Biologique, France). ADP, prostaglandin $E_{1}$ (PGE), theophylline, benzamidine, hirudin, and pepsin were purchased from Sigma Chemical Co. (St. Louis, MO). In the studies of afibrinogenemic platelets, thrombin from Roche Pharmaceuticals (Basel, Switzerland) was used. Bovine serum albumin was from Calbiochem-Behring Corp. (La Jolla, CA), and Triton X 100 was from Eastman Kodak Co. (Rochester, NY). Molecular weight standards were obtained from BioRad Laboratories (Richmond, CA). Human IgG was from Pentex, Division of Miles Laboratories, Inc. (Elkhart, IL).

\section{Results}

Role of platelet fibrinogen in plasminogen binding. Expression of platelet fibrinogen on the cell surface is a consequence of platelet stimulation (41) and fibrinogen is present at sufficient concentrations in platelets (24) to account for plasminogen binding on a stoichiometric basis. Therefore, the role of platelet fibrinogen in plasminogen binding was assessed by examining ${ }^{125}$ I-plasminogen binding to platelets congenitally deficient in intracellular fibrinogen. At the time of this analysis, the patient's plasma and platelet fibrinogen levels were 0.35 and $4.6 \%$ of the normal control, respectively. Maintaining the ${ }^{125}$ I-plasminogen at a $0.2-\mu \mathrm{M}$ concentration, varying concentrations of unlabeled plasminogen ranging from $0.7 \mu \mathrm{M}$ to $9.4 \mu \mathrm{M}$ were added to the normal and afibrinogenemic platelets. The specific binding isotherms derived from the dose-dependent inhibition of ${ }^{125}$ I-plasminogen binding by unlabeled plasminogen for the unstimulated afibrinogenemic and control normal platelets drawn in parallel are shown in Fig. $1 A$. Under this condition, the binding curves were very similar. When these data were analyzed in Scatchard plots, 32,800 molecules were bound per cell and $50 \%$ saturation of the binding sites was achieved at $1.25 \mu \mathrm{M}$ plasminogen for the unstimulated afibrinogenemic platelets while control platelets bound 28,000 molecules/cell with $50 \%$ saturation occurring at $2.3 \mu \mathrm{M}$ plasminogen. These values are very similar to the binding parameters previously determined (4) for unstimulated platelets: dissociation constant $\left(K_{\mathrm{d}}\right)=1.9 \pm 0.2 \mu \mathrm{M}$ and $37,000 \pm 10,500$ plasminogen molecules bound per cell. Thus, plasminogen binding to unstimulated platelets appears to occur independently of the platelet content of fibrinogen. In contrast, plasminogen binding obtained with the thrombin-stimulated afibrinogenemic and normal platelets differed significantly. When $0.2 \mu \mathrm{M}^{125} \mathrm{I}-$ plasminogen was added, the afibrinogenemic platelets bound 10,700 molecules/platelet, whereas 35,300 molecules bound to the normal control platelets prepared in parallel. The binding isotherms for plasminogen binding to thrombin-stimulated afibrinogenemic and normal platelets are shown in Fig. $1 \mathrm{~B}$. At the highest input concentration of the plasminogen, $9.6 \mu \mathrm{M}$, the afibrinogenemic platelets specifically bound 51,000 molecules per platelet compared with the binding of 128,000 plasminogen molecules to the normal control platelets, a 2.5 -fold difference. These differences in the number of binding sites were observed

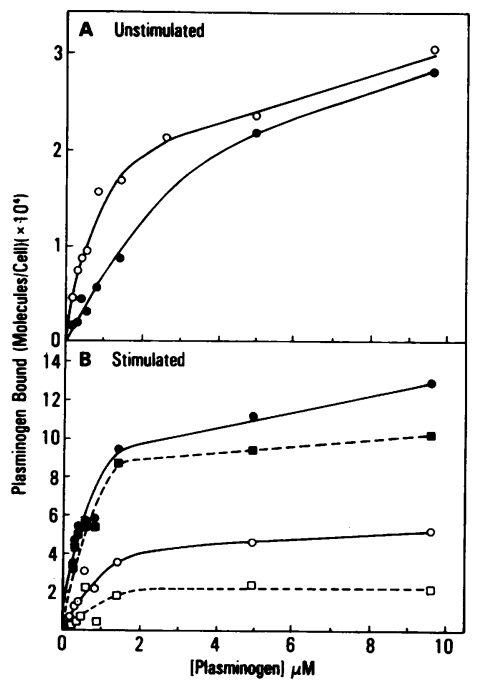

Figure 1. Specific binding of plasminogen to afibrinogenemic (o) and control platelets $(\bullet)$ as a function of plasminogen concentration. $A$, the platelets are unstimulated. Washed platelets at $4.4 \times 10^{7} / \mathrm{ml}$ were incubated with $0.18 \mu \mathrm{M}^{125} \mathrm{I}$ plasminogen, $2.5 \mathrm{mM}$ theophylline, $9 \mu \mathrm{M} \mathrm{PGE}_{1}$, and increasing concentrations of unlabeled plasminogen from $0.73 \mu \mathrm{M}$ to $9.4 \mu \mathrm{M}$ at $22^{\circ} \mathrm{C}$ for $30 \mathrm{~min}$. Specific binding was determined as described in the text. In $B$, the platelets are thrombin stimulated; $\mathrm{PGE}_{1}$ and theophylline were omitted and

the platelets were stimulated with $1 \mathrm{U} / \mathrm{ml}$ alpha-thrombin. The dashed lines are the curves derived by subtracting unstimulated binding in $A$ from stimulated binding in $B$ at each input plasminogen concentration for afibrinogenemic ( $\square$ ) and control ( $\square$ ) cells.

although the apparent dissociation constants, $K_{\mathrm{d}}$, of the afibrinogenemic and normal platelets were similar; 1.5 and $0.7 \mu \mathrm{M}$, respectively, as determined by Scatchard plots of the data. If it is assumed that the plasminogen binding sites on resting platelets remain available and contribute to the total binding to stimulated platelets (an assumption supported by subsequent experiments), then the differences in the number of binding sites become even more dramatic. Such derivative curves have been constructed in Fig. $1 B$. As shown, at the $9.6-\mu \mathrm{M}$ plasminogen input concentration, the number of additional plasminogen molecules bound to the normal and afibrinogenemic platelets are calculated to be 101,000 and 20,800, respectively, a 4.9-fold difference.

As only one afibrinogenemic patient was available for study, Gray platelets that are deficient in alpha-granule proteins including fibrinogen were used to corroborate these results. The Gray platelets also showed selective reduction in thrombinstimulated plasminogen binding. At $15.2 \mu \mathrm{m}$ plasminogen, unstimulated Gray platelets bound 59,700 molecules/cell compared with 30,900 molecules/cell on control platelets isolated in parallel. In contrast, thrombin enhanced ligand binding to the Gray platelets to a level of only 98,300 molecules/cell compared with 240,000 molecules/cell for the normal platelets prepared in parallel. If the levels of unstimulated binding are subtracted, the difference in the extent of stimulated binding to the normal and Gray platelets differed by 5.4-fold.

As an independent approach to assess the role of fibrinogen and its receptor in plasminogen binding to platelets, we determined the relationship between ${ }^{125}$ I-plasminogen binding, ${ }^{125} \mathrm{I}$ fibrinogen binding, and surface expression of fibrinogen, utilizing radiolabeled $\mathrm{F}\left(\mathrm{ab}^{\prime}\right)_{2}$ fragments of anti-fibrinogen, with different platelet stimuli. The following points are illustrated from the results shown in Table I. First, stimulation of platelets with ADP, ADP + epinephrine, calcium ionophore, and a low dose of gamma-thrombin did not enhance ${ }^{125} \mathrm{I}$-plasminogen binding relative to unstimulated platelets. These stimuli did expose fibrinogen receptors on the platelet surface and did induce expression of fibrinogen-related antigen on the platelet surface as indicated by the increased binding of ${ }^{125}$ I-fibrinogen and ${ }^{125}$ I- 
Table I. Relationship between Plasminogen Binding and the Expression of Platelet Fibrinogen, and the Binding of Plasma Fibrinogen to Stimulated Platelets*

\begin{tabular}{lccc}
\hline & \multicolumn{2}{c}{ Molecules/cell } & \\
\cline { 2 - 3 } & 125I-Plasminogen & ${ }^{125}$ I-Fibrinogen & \\
\hline Stimulus & & & 1,542 \\
None & 2,248 & 492 & 92,507 \\
Alpha-thrombin $(1 \mathrm{mU} / \mathrm{ml})$ & 10,682 & 23,390 & 88,306 \\
Gamma-thrombin $(20 \mathrm{mU} / \mathrm{ml})$ & 2,247 & 14,409 & 57,680 \\
ADP $(10 \mu \mathrm{M})$ & 2,668 & 6,532 & 85,246 \\
ADP $(0.5 \mu \mathrm{M})+$ Epinephrine $(7.5 \mu \mathrm{M})$ & 2,646 & 8,745 & 123,444
\end{tabular}

\begin{abstract}
* Platelets at a final concentration of $1 \times 10^{8}$ cells $/ \mathrm{ml}$ were incubated with the indicated stimuli for $30 \mathrm{~min}$ at $22^{\circ} \mathrm{C}$ in Tyrode's-albumin buffer containing $1 \mathrm{mM}$ calcium. Hirudin at a 10-fold excess over the alpha thrombin concentration was added to tubes containing thrombin and incubated for $5 \mathrm{~min}$ at $22^{\circ} \mathrm{C}$ followed either by $0.2 \mu \mathrm{M}^{125} \mathrm{I}$-plasminogen, $0.3 \mu \mathrm{M}^{125} \mathrm{I}$-fibrinogen, or ${ }^{125} \mathrm{I}$-anti-fibrinogen $\mathrm{F}\left(\mathrm{ab}^{\prime}\right)_{2}$ fragments at $4.4 \times 10^{-8} \mathrm{M}$. Binding of these ligands was measured after an additional $30 \mathrm{~min}$ at $22^{\circ} \mathrm{C}$. For the unstimulated condition, platelets were incubated with $2.5 \mathrm{mM}$ theophylline and $9 \mu \mathrm{M} \mathrm{PGE}_{1}$. $¥$ At this concentration of ionophore A23187, 23\% lysis of Indium-labeled platelets was observed. These data were obtained using $0.2 \mu \mathrm{M}$ plasminogen and similar results were also obtained with plasminogen added at a 10 -fold higher input concentration.
\end{abstract}

anti-fibrinogen $F\left(a b^{\prime}\right)_{2}$ fragments. Thus, surface expression of fibrinogen and its receptor is not sufficient to augment ${ }^{125} \mathrm{I}$ plasminogen binding to platelets. Second, stimulation of platelets with a low dose of alpha-thrombin augmented plasminogen binding by approximately fivefold. This stimulation was associated with expression of fibrinogen receptors and fibrinogenrelated antigen. Expression of fibrinogen-related antigen under this condition was, however, not greater than with other platelet stimuli (e.g., calcium ionophore). Even though more fibrinogen binding sites were available on the thrombin-stimulated platelets than with the cells stimulated with the other agonists, it is noted that an 18-fold increase in fibrinogen receptors (ADP + epinephrine vs. the resting platelets) augmented plasminogen binding by only 1.2-fold. Therefore, surface expression of fibrinogen receptors and fibrinogen-related antigen are not sufficient to augment ${ }^{125}$ I-plasminogen binding and only thrombin stimulation alters the extent of the interaction.

Of the platelet agonists, thrombin is unique in its capacity to convert fibrinogen to fibrin. To assess the role of fibrin formation in augmented plasminogen binding, the effects of gamma-thrombin, a proteolytic derivative of alpha-thrombin which has reduced fibrin converting activity relative to its platelet stimulatory effects (42), was compared with alpha-thrombin on ${ }^{125}$ I-plasminogen binding. The release of fibrinopeptide A from platelets stimulated with alpha-thrombin and gamma-thrombin was measured to monitor the extent of fibrin formation. As shown in Table II, both alpha-thrombin and gamma-thrombin increased ${ }^{125}$ I-plasminogen binding to platelets in a dose-dependent manner. With both thrombin forms, enhanced plasminogen binding was observed at concentrations of the stimuli which induced detectable fibrinopeptide A release. At low doses of alpha-thrombin and gamma-thrombin, the extent of ${ }^{125} \mathrm{I}$-plasminogen binding was similar to that observed with unstimulated platelets, and no fibrinopeptide A release was detected. At doses exceeding $5 \mathrm{mU} / \mathrm{ml}$ alpha-thrombin and $88 \mathrm{mU} / \mathrm{ml}$ gammathrombin, ${ }^{125}$ I-plasminogen binding was augmented and fibrinopeptide A release was detected.

Role of platelet membrane proteins in plasminogen binding. To explore the role of the major membrane glycoprotein, GPIIb/
IIIa, in plasminogen binding, the interaction of the ligand with thrombasthenic platelets was evaluated. Platelets from two thrombasthenic patients were utilized. The platelets from these patients have been previously characterized as having reduced levels of GPIIb/IIIa (36) as well as having a deficit in fibrinogen receptor expression and in intracellular fibrinogen (43). From the studies described above, a reduction in thrombin-stimulated binding of plasminogen to these platelets is anticipated due to

Table II. Plasminogen Binding and Fibrinopeptide A Release in Response to Alpha or Gamma Thrombin

\begin{tabular}{lll}
$\begin{array}{l}\text { Concentration } \\
\text { alpha thrombin }\end{array}$ & $\begin{array}{l}\text { 125I-Plasminogen* } \\
\text { bound }\end{array}$ & $\begin{array}{l}\text { Fibrinopeptide A } \\
\text { release }\end{array}$ \\
\hline$U / m l$ & molecules/cell & $\begin{array}{l}\mu g / \text { ml fibrinogen } \\
\text { equivalents }\end{array}$ \\
0 & 2,653 & $<0.04$ \\
$5 \times 10^{-4}$ & 1,761 & $<0.04$ \\
$5 \times 10^{-3}$ & 6,149 & 1.4 \\
$2 \times 10^{-2}$ & 7,938 & 1.3 \\
$1 \times 10^{-1}$ & 15,763 & 1.6 \\
Concentration & & \\
gamma thrombin & & \\
\hline$U / m l$ & & \\
0 & 2,653 & $<0.04$ \\
$2.2 \times 10^{-2}$ & 2,718 & $<0.04$ \\
$8.8 \times 10^{-2}$ & 4,850 & 0.8 \\
$1.3 \times 10^{-1}$ & 5,210 & 0.7 \\
$4.4 \times 10^{-1}$ & 6,647 & 1.3 \\
$8.8 \times 10^{-1}$ & 6,800 & 1.3
\end{tabular}

$1 \times 10^{8} / \mathrm{ml}$ washed human platelets were incubated with $0.2 \mu \mathrm{M}^{125} \mathrm{I}$ plasminogen* or buffert and thrombin for $30 \mathrm{~min}$ at $22^{\circ} \mathrm{C}$. Samples were either centrifuged through sucrose to determine ${ }^{125} \mathrm{I}$-plasminogen binding or incubated for $5 \mathrm{~min}$ with $20 \mathrm{U} / \mathrm{ml}$ hirudin and centrifuged to obtain supernatants that were assayed for fibrinopeptide A release as described in Methods. 
the reduction in platelet fibrinogen. This is borne out by the analyses shown in Fig. $2 \mathrm{~A}$. The specific plasminogen binding isotherms obtained with the platelets from these two thrombasthenic platelets clearly saturated at lower concentrations of plasminogen than the normal platelets isolated in parallel. At an input concentration of $5.7 \mu \mathrm{M}$ plasminogen, the binding to the thrombasthenic platelets was 5.6-fold and 3.8-fold lower than that observed with the normal platelets prepared in parallel. This reduction in total plasminogen binding was even more extensive than observed with the afibrinogenemic patient. The basis for this marked reduction in plasminogen binding to the thrombasthenic platelets became evident when plasminogen binding to unstimulated platelets was analyzed (Fig. $2 B$ ). No saturable binding to the platelets of either thrombasthenic patient was observed. Therefore, GPIIb/IIIa appears to be involved in binding of plasminogen to unstimulated platelets.

We have described a Guamanian family with an unusual variant of Glanzmann's Thrombasthenia, the Cam Variant, first recognized by Dr. A. Lightsey (37). The platelets from this family do not aggregate in response to a variety of stimuli, do not bind fibrinogen, and have reduced intracellular fibrinogen but have normal levels of GPIIb/IIIa accessible to surface radioiodination. Plasminogen binding to thrombin-stimulated and unstimulated platelets from one of these patients has been analyzed in Fig. 3. Unstimulated platelets from this patient bound plasminogen in a very similar fashion to normal control platelets (Fig. $3 A$ ). For example, at a $8 \mu \mathrm{M}$ plasminogen concentration, the platelets of the patient bound 35,500 molecules/platelet compared with 33,000 molecules to the normal platelets. Thrombin-stimulated binding of plasminogen to the patient's platelets was, however, reduced (Fig. $3 B$ ) and this was also observed for another affected

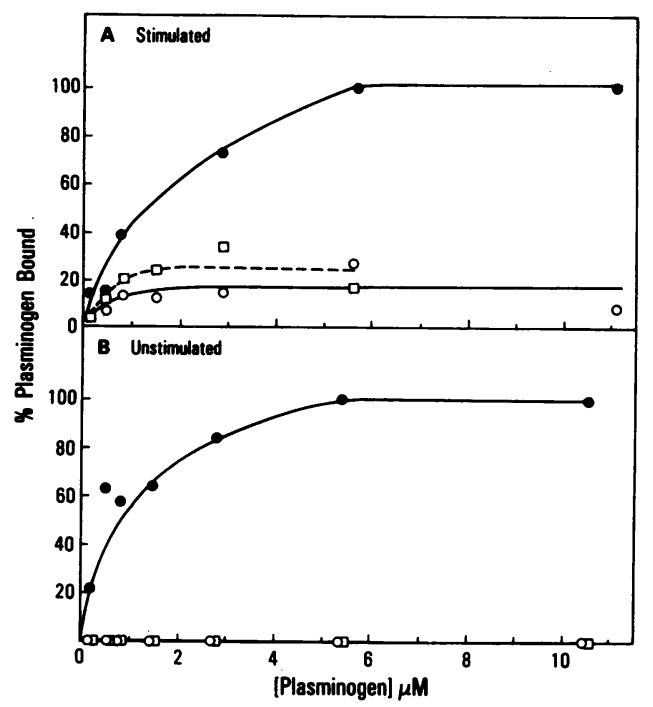

Figure 2. Specific binding of plasminogen to stimulated thrombasthenic $(0, \square)$ and control platelets $(\bullet)$ as a function of plasminogen concentration. In $A$, the platelets are thrombin-stimulated. Washed platelets at $5 \times 10^{7} / \mathrm{ml}$ were incubated with $0.1 \mu \mathrm{M}^{125} \mathrm{I}$-plasminogen, $0.1 \mathrm{U} / \mathrm{ml}$ thrombin, and increasing concentrations of unlabeled plasminogen from $0.35 \mu \mathrm{M}$ to $11.1 \mu \mathrm{M}$ and incubated at $22^{\circ} \mathrm{C}$ for 30 $\min$. In $B$, the platelets are unstimulated; $2.5 \mathrm{mM}$ theophylline and $9 \mu \mathrm{M} \mathrm{PGE}_{1}$ were substituted for the thrombin, and platelets were used at a concentration of $1 \times 10^{8} \mathrm{ml}$. Unstimulated control platelets bound 8,100 molecules per cell at saturation, and binding was enhanced 3.2-fold in the presence of thrombin.

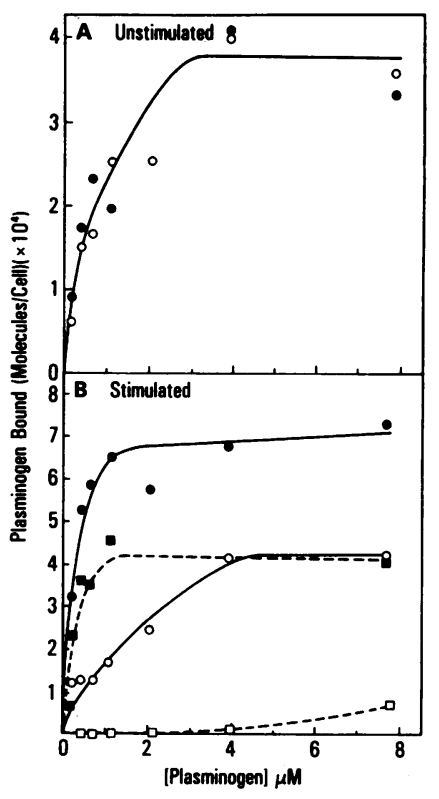

Figure 3. Specific binding of plasminogen to Cam Variant platelets (o) and control platelets $(\bullet)$ as a function of plasminogen concentration. In $A$, the platelets are unstimulated and were incubated with 2.5 $\mathrm{mM}$ theophylline and $9 \mu \mathrm{M}$ $\mathrm{PGE}_{1}$, and in $B$ the platelets are stimulated with $0.1 \mathrm{U} / \mathrm{ml}$ thrombin. Platelets were at 1 $\times 10^{8} / \mathrm{ml},{ }^{125} \mathrm{I}$-plasminogen at $0.2 \mu \mathrm{M}$ and unlabeled plasminogen ranged from $0.23 \mu \mathrm{M}$ to $7.5 \mu \mathrm{M}$. The incubations were at $22^{\circ} \mathrm{C}$ for $30 \mathrm{~min}$. The dashed lines are the curves derived by subtracting unstimulated binding in $A$ from stimulated binding in $B$ at each input plasminogen concentration for Cam Variant ( $\square$ ) and control (a) platelets.

family member whose platelets were tested. When molecules bound per unstimulated cell were subtracted from total binding at each plasminogen concentration, thrombin-induced binding was only observed at the two highest input plasminogen concentrations tested and was only $17 \%$ of the normal control. Thus, the extent of the defect in thrombin-stimulated plasminogen binding to platelets in these patients was more pronounced than for the afibrinogenemic cells, perhaps due to the double deficiency in platelet fibrinogen as well as its receptor.

To establish that abnormalities of platelet membrane proteins do not generally perturb plasminogen binding, the interaction of plasminogen with platelets from a patient with Bernard-Soulier syndrome was investigated. Platelets from patients with BernardSoulier syndrome lack GPIb (44). In addition, recent studies have suggested that these platelets may also be deficient in GPV and a 20,000 mol wt component (45). As shown in Table III, both unstimulated and thrombin stimulated Bernard-Soulier platelets bound plasminogen. Compared with the normal platelets analyzed in parallel, the Bernard-Soulier platelets bound approximately twofold more plasminogen under both stimulated and nonstimulated conditions, which may reflect the larger size of these platelets $(34,44)$. This finding is consistent with a published report showing a twofold enhancement in ${ }^{125} \mathrm{I}-$ von Willebrand Factor binding to thrombin-stimulated Bernard-Soulier platelets compared with control platelets (18). Thus, platelets that are deficient in major membrane proteins are capable of binding plasminogen, which indicates that the deficit in plasminogen binding observed with the thrombasthenic platelets is unique to this syndrome.

The membrane glycoprotein, GPIIb/IIIa, exist's as a calciumdependent heterodimer (46) in both unstimulated and stimulated platelets $(11,12,39,46-51)$. Calcium chelation at $37^{\circ} \mathrm{C}$ but not $22^{\circ} \mathrm{C}$ has been shown to disrupt the heterodimer on the cell (4750). Therefore, the effect of calcium chelation at these two temperatures on the interaction of plasminogen with platelets was examined (Table IV). Monoclonal antibody AP-2 reacts with the GPIIb/IIIa complex in the presence of calcium but not with GPIIb or GPIIIa in the presence of calcium or EDTA $(39,40)$. Using radioiodinated AP-2, we established that calcium chelation 
Table III. Plasminogen Binding to Bernard-Soulier Platelets

\begin{tabular}{|c|c|c|c|c|}
\hline \multirow[b]{3}{*}{$\begin{array}{l}\text { Concentration } \\
\text { plasminogen }\end{array}$} & \multicolumn{4}{|c|}{ Percent of control* } \\
\hline & \multicolumn{2}{|c|}{ Unstimulated } & \multicolumn{2}{|c|}{ Stimulated $\S$} \\
\hline & $\begin{array}{l}\text { Bernard- } \\
\text { Soulier }\end{array}$ & Control & $\begin{array}{l}\text { Bernard- } \\
\text { Soulier }\end{array}$ & Control \\
\hline \multicolumn{5}{|l|}{$\mu M$} \\
\hline 25.2 & 187 & 100 & 190 & 100 \\
\hline 6.5 & 105 & 35 & 48 & 32 \\
\hline 3.3 & 83 & 24 & 43 & 17 \\
\hline 1.8 & 54 & 21 & 35 & 17 \\
\hline 0.6 & 34 & 16 & 19 & 10 \\
\hline 0.2 & 18 & 19 & 12 & 7 \\
\hline
\end{tabular}

* Percent binding was calculated relative to plasminogen binding by control platelets at a $25.2 \mu \mathrm{M}$ plasminogen concentration. This value was 140,000 molecules/platelet for stimulated and 21,400 molecules/ platelet for unstimulated control cells.

$\ddagger$ Washed platelets at $1 \times 10^{8} / \mathrm{ml}$ were incubated with $0.2 \mu \mathrm{M}^{125} \mathrm{I}$ plasminogen, $2.5 \mathrm{mM}$ theophylline, $9 \mu \mathrm{M} \mathrm{PGE}_{1}$ and unlabeled plasminogen at the indicated concentrations for $30 \mathrm{~min}$ at $22^{\circ} \mathrm{C}$.

$\S$ Washed platelets at $1 \times 10^{8} / \mathrm{ml}$ were incubated with $0.2 \mu \mathrm{M}^{125} \mathrm{I}-$ plasminogen, $0.1 \mathrm{U} / \mathrm{ml}$ thrombin, and unlabeled plasminogen at the indicated concentrations for $30 \mathrm{~min}$ at $22^{\circ} \mathrm{C}$.

with EDTA or Mg-EGTA at $37^{\circ} \mathrm{C}$ reduced expression of the AP-2 epitope on our stimulated and nonstimulated platelet preparations by $>90 \%$ and reduced the epitope by $<10 \%$ at $22^{\circ} \mathrm{C}$. Calcium chelation at $37^{\circ} \mathrm{C}$ had a differential effect on plasminogen binding to thrombin-stimulated and unstimulated platelets. Thrombin-stimulated binding was markedly reduced ( $\geq 83 \%$ inhibition). In contrast, treated, unstimulated platelets at $37^{\circ} \mathrm{C}$ retained their capacity to bind plasminogen. In the experiment shown in Table IV, Mg-EGTA caused a 10\% inhibition of plasminogen binding to the unstimulated platelets. In five similar experiments, the mean extent of inhibition under this condition was $26 \pm 19 \%$. The inhibition observed in the presence of EDTA was $12 \pm 14 \%$ (10 experiments). Thus, conditions that dissociated the GPIIb/IIIa complex had a limited effect on plasminogen binding to unstimulated platelets. At $22^{\circ} \mathrm{C}$, calcium chelation caused partial reduction in both stimulated and nonstimulated plasminogen binding. With thrombin-stimulated platelets at both temperatures, plasminogen binding and surface expression of fibrinogen, as measured by $\mathrm{F}\left(\mathrm{ab}^{\prime}\right)_{2}$ antibody binding, exhibited parallel changes. Note that EDTA did not fully inhibit surface expression of fibrinogen at $22^{\circ} \mathrm{C}$ even though the binding of exogenous fibrinogen is divalent ion-dependent (32). This observation is consistent with our previous data (41) suggesting that surface expression of endogenous fibrinogen and binding of exogenous fibrinogen may involve distinct mechanisms. In the experiments described above, thrombin and the chelating agents were added simultaneously to the platelets. Similar results were obtained when the platelets were first stimulated with thrombin and then treated with EDTA. At an input ${ }^{125}$ I-plasminogen concentration of $0.2 \mu \mathrm{M}$, platelets prestimulated with thrombin for $5 \mathrm{~min}$ before a 30-min treatment with EDTA bound 4,900 \pm 330 plasminogen molecules/cell compared with $5,400 \pm 130$ molecules/cell when thrombin and EDTA were added simultaneously to the platelets. These levels represented 74 and $71 \%$ inhibition, respectively, of the binding obtained with thrombin-stimulated platelets which were not exposed to EDTA.

\section{Discussion}

We have previously shown that Glu-plasminogen binds specifically to resting platelets and that thrombin stimulation of the cells augments the extent of the interaction by approximately

Table IV. Effects of Calcium Chelation on Plasminogen Binding and Surface Expression of Platelet Fibrinogen*

\begin{tabular}{|c|c|c|c|c|c|c|c|c|}
\hline & \multicolumn{4}{|l|}{$37^{\circ} \mathrm{C}$} & \multicolumn{4}{|l|}{$22^{\circ} \mathrm{C}$} \\
\hline & \multicolumn{2}{|l|}{${ }^{125}$ I-Plasminogen } & \multicolumn{2}{|c|}{${ }^{125} \mathrm{I}$-anti-fibrinogen $\mathrm{F}(\mathrm{ab})_{2}$} & \multicolumn{2}{|c|}{${ }^{125}$ I-Plasminogen } & \multicolumn{2}{|c|}{${ }^{125} \mathrm{I}$-anti-fibrinogen $\mathrm{F}(\mathrm{ab})_{2}$} \\
\hline & Molecules/cell & $\begin{array}{l}\text { Percent } \\
\text { boundf }\end{array}$ & Molecules/cell & $\begin{array}{l}\text { Percent } \\
\text { boundf }\end{array}$ & Molecules/cell & $\begin{array}{l}\text { Percent } \\
\text { bound }\end{array}$ & Molecules/cell & $\begin{array}{l}\text { Percent } \\
\text { bound }\end{array}$ \\
\hline \multicolumn{9}{|l|}{ Unstimulated } \\
\hline 5 mM EDTA & $1,414 \pm 200$ & 100 & $<3,200$ & - & $985 \pm 114$ & 62 & $<3,200$ & - \\
\hline \multicolumn{9}{|c|}{$1 \mathrm{mM} \mathrm{Mg}^{++}+5 \mathrm{mM}$} \\
\hline EGTA & $880 \pm 97$ & 90 & $<3,200$ & - & $784 \pm 25$ & 49 & $<3,200$ & - \\
\hline $1 \mathrm{mM} \mathrm{Ca}^{++}$ & $980 \pm 89$ & 100 & $<3,200$ & - & $1,598 \pm 199$ & 100 & $<3,200$ & - \\
\hline \multicolumn{9}{|c|}{ Thrombin-stimulated } \\
\hline 5 mM EDTA & $959 \pm 52$ & 13 & $6,229 \pm 607$ & 15 & $4,464 \pm 19$ & 50 & $14,325 \pm 610$ & 70 \\
\hline \multicolumn{9}{|c|}{$1 \mathrm{mM} \mathrm{Mg}^{++}+5 \mathrm{mM}$} \\
\hline EGTA & $1,252 \pm 38$ & 17 & $1,329 \pm 463$ & 3 & $6,869 \pm 471$ & 76 & $6,313 \pm 939$ & 31 \\
\hline $1 \mathrm{mM} \mathrm{Ca}^{++}$ & $7,567 \pm 735$ & 100 & $41,145 \pm 5,185$ & 100 & $8,989 \pm 178$ & 100 & $20,389 \pm 1,152$ & 100 \\
\hline
\end{tabular}

* Platelets were incubated with thrombin or buffer in the presence of $\mathrm{Ca}^{++}$, EDTA, or $\mathrm{Mg}^{++}-\mathrm{EGTA}$ for 30 min at $37^{\circ} \mathrm{C}$. Hirudin was added to thrombin-containing samples and incubation was continued for $5 \mathrm{~min}$. ${ }^{125} \mathrm{I}$-plasminogen, $0.16 \mu \mathrm{M}$, or ${ }^{125} \mathrm{I}$-anti-fibrinogen $\mathrm{F}\left(\mathrm{ab}^{\prime}\right)_{2}, 4.4 \times 10^{-8} \mathrm{M}$, was added and mixtures were further incubated for $30 \mathrm{~min}$ at the indicated temperatures. The final thrombin concentration was $0.1 \mathrm{U} / \mathrm{ml}$ and the final platelet concentration was $1 \times 10^{8} \mathrm{cells} / \mathrm{ml}$. The data shown are the means \pm SD from triplicate determinations which are representative of 10 experiments with EDTA and five experiments with $\mathrm{Mg}^{++}+$EGTA. $¥$ Percent bound is calculated, relative to the sample containing $\mathrm{Ca}^{++}$at each temperature, for either stimulated or unstimulated cells. 
fivefold (4). As the affinity of plasminogen for unstimulated and thrombin stimulated platelets was similar, it was not established if these interactions occurred through the same or through independent mechanisms. In the present study we have used washed human platelets and Glu-plasminogen to provide evidence that these interactions are distinct from one another. This conclusion is based primarily upon the identification of three types of congenitally deficient platelets-afibrinogenemic, Gray, and Cam Variant thrombasthenic-which exhibited normal plasminogen binding to unstimulated cells but markedly reduced thrombin dependent binding. The increase in thrombin-stimulated binding relative to unstimulated binding to these platelets was 1.7-fold, 2.6-fold, and 1.2-fold, respectively, as contrasted to the fivefold augmentation in normal platelets. The common feature shared by these platelets is their deficit of intracellular fibrinogen. While Gray and Cam Trait thrombasthenic platelets have additional abnormalities, fibrinogen deficiency is the only known abnormality attributed to afibrinogenemic platelets. Since the platelets from these patients were not totally deficient in fibrinogen, the slight augmentation of plasminogen binding upon thrombin stimulation may be dependent upon the low levels of platelet fibrinogen in these cells. The stimulus requirements for augmentation of plasminogen binding to platelets additionally indicated that the role of platelet fibrinogen in the interaction is contingent upon its conversion to fibrin. Various stimuli including ADP, calcium ionophore, and ADP plus epinephrine induced surface expression of fibrinogen-related antigen but did not enhance plasminogen binding to the cells. Thrombin was unique in this capacity, and high concentrations of either alphathrombin or gamma-thrombin were capable of increasing plasminogen binding. These thrombin forms enhanced plasminogen binding under conditions where conversion of fibrinogen to fibrin was detected. Thus, it is suggested that enhanced plasminogen binding to thrombin-stimulated platelets is dependent upon both the availability of platelet fibrinogen and upon its conversion to fibrin.

The differential effects of calcium chelation at $37^{\circ} \mathrm{C}$ on plasminogen binding to thrombin-stimulated and unstimulated platelets-marked inhibition of stimulated binding as contrasted with minimal inhibition of unstimulated binding - further support the existence of two distinct mechanisms of plasminogen binding to platelets. The marked reduction in plasminogen binding to unstimulated thrombasthenic platelets suggests that GPIIb/IIIa is required for this interaction. The intact heterodimeric form of GPIIb/IIIa does not appear to be necessary for this interaction since plasminogen did bind to unstimulated platelets under conditions (at $37^{\circ} \mathrm{C}$ in the absence of calcium) which dissociate the complex (46-49) and destroy the epitope recognized by AP-2. Thus, the GPIIb or GPIIIa subunits may be sufficient to support unstimulated plasminogen binding. Aggregation of dissociated GPIIb and GPIIIa has been reported $(47,50)$, and this may explain the greater variability in plasminogen binding under dissociating conditions observed with unstimulated platelets (see Table IV). Under conditions which cause complex dissociation (at $37^{\circ} \mathrm{C}$ in the presence of EDTA), a marked reduction in both thrombin-stimulated plasminogen binding and fibrin(ogen) surface expression was observed. Thus, via its interaction with fibrinogen, the GPIIb/IIIa complex may also participate in plasminogen binding to thrombin-stimulated platelets. At $22^{\circ} \mathrm{C}$, calcium chelating agents affected plasminogen binding to both stimulated and unstimulated platelets to a partial extent. The basis for this effect may relate to additional roles of divalent ions on the structure/conformation of GPIIb and GPIIIa. Recently, evidence for two additional calcium binding sites, distinct from that maintaining the GPIIb/IIIa complex, with dissociation constants in the $\mu \mathrm{M}$ and $\mathrm{mM}$ range has been provided $(52,53)$. We have previously reported (4) that EDTA did not affect plasminogen binding to platelets at $22^{\circ} \mathrm{C}$. The difference between the present study and our previous results relates to the preincubation of the platelets with the chelating agents before addition of ${ }^{125} \mathrm{I}$-plasminogen. Since preincubation of platelets with chelating agents is necessary to reduce plasminogen binding, an indirect effect of the chelating agents on platelets at $22^{\circ} \mathrm{C}$ such as to alter plasminogen binding may be considered.

The identification of fibrin and GPIIb/IIIa as candidate plasminogen binding sites does not exclude a role for other platelet constituents in these interactions. The modulatory roles for other platelet proteins such as thrombospondin may still be considered based upon its plasminogen binding properties (21). It is clear, however, that since thrombospondin is present in thrombasthenic platelets, it is not sufficient to support a major pathway of plasminogen binding to platelets. Also note that plasminogen binding to unstimulated or stimulated Bernard-Soulier platelets was not reduced, which suggests that a major platelet substrate of plasmin cleavage, GPIb, (54) does not serve as a primary plasminogen binding site as previously suggested (55).

It has been estimated with monoclonal antibodies that platelets express 40,000-50,000 GPIIb/IIIa molecules on their surfaces $(11,12)$. This level readily accommodates the binding of plasminogen to unstimulated platelets, $37,000 \pm 10,000$ molecules maximally bound, at a 1:1 stoichiometry. The similarity in the extent of plasminogen binding to unstimulated cells and thrombin stimulated afibrinogenemic and Gray platelets suggests that the constitutive binding sites on unstimulated platelets remain available on stimulated cells. Therefore, of the total 190,000 binding sites on thrombin stimulated platelets, $\sim 150,000$ new sites are expressed per platelet. In the absence of platelets, plasminogen binds to fibrin with a 2:1 stoichiometry (22). Therefore, only $50 \%$ of the $\sim 126,000$ platelet fibrinogen molecules would need to become cell-surface associated in order to account for the extent of plasminogen binding to thrombin stimulated platelets. This level is greater than would be predicted if surface expression simply involved secretion and binding of platelet fibrinogen to its cell surface receptor as platelet and plasma fibrinogen bind to platelets with the same affinity (56). However, surface expression of adhesive proteins (57) including fibrinogen (41) may occur by a mechanism independent of their release and rebinding and could account for sufficient association of fibrin with the platelet to support stoichiometric binding of plasminogen. The dissociation constant of Glu-plasminogen, the ligand used in the study, for fibrin in the absence of platelets has been estimated to be $38 \mu \mathrm{M}$ (22). As previously reported (4) and confirmed during the course of this study, the apparent dissociation constant of plasminogen for thrombin stimulated as well as unstimulated platelets is $1-6 \mu \mathrm{M}$. Either the platelet surface enhances the apparent affinity of fibrin for plasminogen or the binding assay utilized has a systematic effect upon the estimation of the affinity of this interaction. Studies with various plasminogen derivatives are presently in progress and should resolve these possibilities.

Our previous data support the suggestion that platelets have the potential to enhance fibrinolysis by localizing plasminogen in a thrombus and enhancing its activation (4). The studies re- 
ported here indicate that the GPIIb/IIIa molecule and platelet fibrin(ogen) may play dual roles in clot formation and dissolution. Initially, these molecules are required for platelet aggregation and thrombus formation. In addition, these molecules are also required for plasminogen binding which may ultimately promote clot dissolution.

\section{Acknowledgments}

We thank Dr. Margaret Johnson, Wilmington Medical Center, Wilmington, DE for allowing us to study the thrombasthenic and BernardSoulier platelets, Dr. Gerard Marguerie, INSERM U217, Grenoble, France, for providing the afibrinogenomic platelets, Dr. Alton Lightsey, F. Edward Hebert School of Medicine, Uniformed Health Service University of the Health Sciences, Bethesda, MD, for providing the Cam Variant thrombasthenic platelets, Dr. Thomas Kunicki, Blood Center of Southeastern Wisconsin, Milwaukee, WI, for providing the AP-2 antibody, Vicky Byers-Ward for preparing anti-fibrinogen $\mathrm{F}\left(\mathrm{ab}^{\prime}\right)_{2}$ fragments, Carol Fode for excellent technical assistance, and Ellen Schmeding for excellent secretarial assistance. Blood drawing was performed in part by the General Clinical Research Center of Scripps Clinic and Research Foundation, supported by National Institutes of Health grant RR-00833. Dr. L. Miles was supported by American Heart Association, California Affiliate Fellowship 84-S13. This work was supported by National Institutes of Health grants HL-17964 and HL-28235. This is publication No. 4073-IMM from the Department of Immunology, Research Institute of Scripps Clinic.

\section{References}

1. Thorsen, S., P. Brakman, and T. Astrup. 1972. Influence of platelets on fibrinolysis: A critical review. In Hematologic Reviews. Vol. 3. Ambrose, J. L., editor. Marcel Dekker, Inc., New York. 123-179.

2. Joist, J. H. 1977. Platelets and fibrinolysis. Thromb. Haemostasis. 38:955-962.

3. Morse, E. E., D. P. Jackson, and C. L. Conley. 1965. Role of platelet fibrinogen in the reactions of platelets to thrombin. J. Clin. Invest. 44:809-816.

4. Miles, L. A., and E. F. Plow. 1985. Binding and activation of plasminogen on the platelet surface. J. Biol. Chem. 260:4303-4311.

5. Wiman, B., and D. Collen. 1977. Purification and characterization of human antiplasmin, the fast-acting plasmin inhibitor in plasmin. Eur. J. Biochem. 78:19-26.

6. Moroi, M., and N. Aoki. 1976. Isolation and characterization of alpha 2 -plasmin inhibitor from human plasma. J. Biol. Chem. 251:59565965.

7. Lijnen, H. R., M. Hoylaerts, and D. Collen. 1980. Isolation and characterization of a human plasma protein with affinity for the lysine binding sites in plasminogen. J. Biol. Chem. 255:10214-10222.

8. Plow, E. F., and D. Collen. 1981. The presence and release of alpha ${ }_{2}$-antiplasmin from human platelets. Blood. 58:1069-1074.

9. Leung, L. L. K., P. C. Harpel, R. L. Nachman, and E. M. Rabellino. 1983. Histidine-rich glycoprotein is present in human platelets and is released following thrombin stimulation. Blood. 62:1016-1021.

10. Coller, B. S., E. I. Peerschke, L. E. Scudder, and C. A. Sullivan. 1983. Studies with a murine monoclonal antibody that abolishes ristocetin-induced binding of von Willebrand Factor to platelets: Additional evidence in support of GPIb as a platelet receptor for von Willebrand Factor. Blood. 61:99-110.

11. McEver, R. P., E. M. Bennet, and M. N. Martin. 1983. Identification of two structurally and functionally distinct sites on human platelet membrane glycoprotein IIb-IIIa using monoclonal antibodies. J. Biol. Chem. 258:5269-5275.

12. Coller, B. S., E. I. Peerschke, L. E. Scudder, and C. A. Sullivan. 1983. A murine monoclonal antibody that completely blocks the binding of fibrinogen to platelets produces a thrombasthenic-like state in normal platelets and binds to glycoproteins IIb and/or IIIa. J. Clin. Invest. 72: 325-338.
13. Moake, J. L., J. D. Olson, J. H. Troll, S. S. Tang, T. Funicella, and D. M. Peterson. 1980. Binding of radioiodinated human von Willebrand Factor to Bernard-Soulier, thrombasthenic, and von Willebrand's disease platelets. Thromb. Res. 19:21-27.

14. Plow, E. F., and G. Marguerie. 1980. Participation of ADP in the binding of fibrinogen to thrombin-stimulated platelets. Blood. 56: 553-556.

15. Bennett, J. S., and G. Vilaire. 1979. Exposure of platelet fibrinogen receptors by ADP and epinephrine. J. Clin. Invest. 64:1393-1401.

16. Bennett, J. S., J. A. Hoxie, S. F. Leitman, G. Vilaire, and D. B. Cines. 1983. Inhibition of fibrinogen binding to stimulated human platelets by a monoclonal antibody. Proc. Natl. Acad. Sci. USA. 80:24172421.

17. Ginsberg, M. H., J. Forsyth, A. Lightsey, J. Chediak, and E. F. Plow. 1983. Reduced surface expression and binding of fibronectin by thrombin-stimulated thrombasthenic platelets. J. Clin. Invest. 71:619624.

18. Ruggeri, Z. M., L. DeMarco, L. Gatti, R. Bader, and R. R. Montgomery. 1983. Platelets have more than one binding site for von Willebrand Factor. J. Clin. Invest. 72:1-12.

19. Phillips, D. R., L. K. Jennings, and H. R. Prasanna. 1980. $\mathrm{Ca}^{2+}-$ mediated association of glycoprotein $\mathrm{G}$ (thrombin-sensitive protein, thrombospondin) with human platelets. J. Biol. Chem. 255:1 1629-11632.

20. George, J. N. 1978. Studies on platelet plasma membranes. IV. Quantitative analysis of platelet membrane glycoproteins by $\left({ }^{125} \mathrm{I}\right)$-diazotized diiodosulfanilic acid labeling and SDS-polyacrylamide gel electrophoresis. J. Lab. Clin. Med. 92:430-446.

21. Silverstein, R. L., L. L. K. Leung, P. C. Harpel, and R. L. Nachman. 1984. Complex formation of platelet thrombospondin with plasminogen. J. Clin. Invest. 74:1625-1633.

22. Lucas, M. A., L. J. Fretto, and P. A. McKee. 1983. The binding of human plasminogen to fibrin and fibrinogen. J. Biol. Chem. 258: $4249-4256$.

23. Ginsberg, M. H., J. D. Wencel, J. G. White, and E. F. Plow. 1983. Binding of fibronectin to alpha-granule-deficient platelets. J. Cell Biol. 97:571-573.

24. Gerrard, J. M., D. R. Phillips, G. H. R. Rao, E. F. Plow, D. A. Walz, R. Ross, L. A. Harker, and J. G. White. 1980. Biochemical studies of two patients with the Gray Platelet syndrome. J. Clin. Invest. 66:102109.

25. Deutsch, D. G., and E. T. Mertz. 1970. Plasminogen: purification from human plasma by affinity chromatography. Science (Wash. DC). 170:1995-1996.

26. Robbins, K. C., and L. Summaria. 1976. Plasminogen and plasmin. Methods Enzymol. 45:257-273.

27. Allen, G. 1981. Sequencing of proteins and peptides. Elsevier/ North Holland Publishing Co., Amsterdam. 168-173.

28. Wallen, P., and B. Wiman. 1972. Characterization of human plasminogen. II. Separation and partial characterization of different molecular forms of human plasminogen. Biochim. Biophys. Acta. 257:122134.

29. McConahey, P., and F. Dixon. 1966. A method of trace iodination of proteins for immunologic studies. Int. Arch. Allergy Appl. Immunol. 29:185-189.

30. Plow, E. F., and T. S. Edgington. 1975. Unique immunochemical features and intracellular stability of platelet fibrinogen. Thromb. Res. 7:729-742.

31. Plow, E. F., G. A. Marguerie, and M. H. Ginsberg. 1985. Fibronectin binding to thrombin-stimulated platelets: evidence for fibrin(ogen) independent and dependent pathways. Blood. 66:26-32.

32. Marguerie, G. A., T. S. Edgington, and E. F. Plow. 1980. Interaction of fibrinogen with its platelet receptor as part of a multistep reaction in ADP-induced platelet aggregation. J. Biol. Chem. 255:154-161.

33. Munson, P. J., and D. Rodbard. 1980. Ligand: A versatile computerized approach for characterization of ligand-binding systems. Anal. Biochem. 107:220-239. 
34. Weiss, H. J., T. B. Tshopp, H. R. Baumgartner, I. Sussman, M. M. Johnson, and J. J. Egan. 1974. Decreased adhesion of giant (Bernard-Soulier) platelets to subendothelium. Am. J. Med. 57:920-925.

35. Marguerie, G. A., N. Thomas-Maison, M. J. Larrieu, and E. F. Plow. 1982. Interaction of fibrinogen with platelets in the plasma milieu. Blood. 59:91-96.

36. Peterson, D. M., and B. Wehring. 1981. Isoelectric characteristics and surface radioiodination of normal and thrombasthenic platelet membrane glycoproteins. Thrombos. Res. 22:53-65.

37. Lightsey, A. L., W. J. Thomas, E. F. Plow, R. McMillan, and M. Ginsberg. 1981. Glanzmann's thrombathenia in the absence of glycoprotein IIb and III deficiency. Blood. 58(Suppl. 5):706. (Abstr.)

38. Doolittle, R. F., D. Schubert, and S. A. Schwartz. 1967. Amino acid sequence studies on artiodactyl fibrinopeptide. I. Dromedary camel, mule deer, and cape buffalo. Arch. Biochem. Biophys. 118:456-467.

39. Pidard, D., R. R. Montgomery, J. S. Bennet, and T. J. Kunicki. 1983. Interaction of AP-2, a monoclonal antibody specific for the human platelet glycoprotein IIb-IIIa complex, with intact platelets. J. Biol. Chem. 258:12582-12586.

40. Kunicki, T. 1985. Organization of glycoproteins within platelet plasma membranes. In Platelet Membrane Glycoproteins. George, J. and P. Nurden, editors. Plenum Publishing Co., New York. 87-103.

41. Courtois, G., J.-J. Ryckewaert, M. Ginsberg, V. Woods, Jr., E. Plow, and G. Marguerie. 1984. Surface exposure of platelet fibrinogen. Circulation. 70(Suppl. II):358. (Abstr.)

42. Charo, I. F., R. D. Feinman, and T. C. Detwiler. 1977. Interrelations of platelet aggregation and secretion. J. Clin. Invest. 60:866-873.

43. Kornecki, E., S. Niewiarowski, T. A. Morinelli, and M. Kloczewiak. 1981. Effects of chymotrypsin and adenosine diphosphate on the exposure of fibrinogen receptor on normal human and Glanzmann's thrombasthenic platelets. J. Biol. Chem. 256:5696-5701.

44. Nurden, A. T., D. Dupus, T. J. Kunicki, and J. P. Caen. 1981. Analysis of the glycoprotein and protein composition of Bernard-Soulier platelets by single and two-dimensional sodium dodecyl sulfate-polyacrylamide gel electrophoresis. J. Clin. Invest. 67:1431-1440.

45. Berndt, M. C., C. Gregory, B. H. Cong, H. Zola, and P. A. Castaldi. 1983. Additional glycoprotein defects in Bernard-Soulier's syndrome: Confirmation of genetic basis by parental analysis. Blood. 62:800-807.

46. Jennings, L. K., and D. R. Phillips. 1982. Purification of glyco- proteins IIb and III from human platelet plasma membranes and characterization of a calcium-dependent glycoprotein IIb-III complex. J. Biol. Chem. 257:10458-10463.

47. Fujimura, K., and D. R. Phillips. 1983. Calcium cation regulation of glycoprotein IIb-IIIa complex formation in platelet plasma membranes. J. Biol. Chem. 258:10247-10252.

48. Kunicki, T. J., D. Pidard, J. P. Rosa, and A. T. Nurden. 1981. The formation of $\mathrm{Ca}^{++}$-dependent complexes of platelet membrane glycoproteins IIb and IIIa in solution as determined by crossed immunoelectrophoresis. Blood. 58:268-278.

49. Brass, L. F., S. J. Shattil, T. J. Kunicki, and J. S. Bennet. 1985. Effect of calcium on the stability of the platelet membrane glycoprotein IIb-IIla complex. J. Biol. Chem. 260:7875-7881.

50. Shattil, S. J., L. F. Brass, J. S. Bennet, and P. Pandhi. 1985. Biochemical and functional consequences of dissociation of the platelet membrane glycoprotein IIb-IIIa complex. Blood. 66:92-98.

51. Pidard, D., D. Fournier, and A. T. Nurden. 1985. Incubation of human platelets with EDTA and $37^{\circ} \mathrm{C}$ causes irreversible changes in the organization of membrane glycoproteins IIb and IIIa. Thrombos. Haemostas. 541:50. (Abstr.)

52. Shattil, S. J., J. A. Hoxie, M. C. Cunningham, and L. F. Brass. 1985. Expression of the platelet fibrinogen receptor involves a conformational change in the membrane glycoprotein IIb-IIIa complex. Thrombos. Haemostas. 54:50. (Abstr.)

53. Ginsberg, M. H., T. J. Kunicki, G. Marguerie, and E. F. Plow. 1985. Regulation of the surface orientation of platelet membrane glycoprotein Ilb- $\alpha$. 1985. Thrombos. Haemostas. 54:50. (Abstr.)

54. Adelman, B., A. D. Michelson, J. Loscalzo, J. Greenberg, and R. I. Handin. 1985. Plasmin effect on platelet glycoprotein 1B-von Willebrand Factor interactions. Blood. 65:32-40.

55. Adelman, B., J. Greenberg, A. D. Michelson, and R. I. Handin. 1984. Plasmin degradation of platelet glycoprotein Ib is dependent upon plasmin binding via lysine binding sites. Circulation. 70:II-357. (Abstr.)

56. Kunicki, T. J., P. J. Newman, D. L. Amrani, and M. W. Mosesson. 1985. Human platelet fibrinogen: purification and hemostatic properties. Blood. 66:808-815.

57. Ginsberg, M. H., and E. F. Plow. 1981. Fibronectin expression on the platelet surface occurs in concert with secretion. J. Supramol. Structure Cell. Biochem. 17:91-98. 